\title{
Community Diversity and Donor Control: An empirical analysis of contributions to donor- advised funds at community foundations
}

\author{
Heng Qu \\ The Bush School of Government and Public Service \\ Texas A\&M University \\ Laurie E. Paarlberg \\ Lilly Family School of Philanthropy \\ Indiana University Purdue University Indianapolis
}

\begin{abstract}
This study examines the relationship between community ethnic-racial diversity and contributions to donors-advised funds (DAFs) held by community foundations. Unlike general contributions, DAFs allows donors to retain advisory control over their fund distribution based on individual preferences. In contrast to prior research that generally finds that diversity dampens private provision of public goods, we show that greater ethnic-racial diversity is significantly associated with higher levels of contributions to DAFs at community foundations but not with general contributions. The findings contribute to the literature on diversity and public goods provision and have practical implications for the policy role of private philanthropy.
\end{abstract}

Keywords: diversity, community foundations, donor-advised funds, philanthropy, charitable contributions, public goods 


\section{Introduction}

Local governance increasingly relies upon private philanthropic organizations, such as community foundations, to achieve public policy goals. In particular, community foundations, which are public charities that raise funds and make grants in a geographic community, increasingly play important roles in planning, implementing, and funding local public services (Carman, 2001; Daly, 2008; Graddy \& Morgan, 2006; Phillips \& Jung, 2016). However, there are critiques that private philanthropy is unresponsive to the changing needs of a diverse population and serves the elite interests of donors, who also unduly benefit from the tax benefits associated with their contributions (Giridharadas, 2019; Reich, 2018; Reich et al., 2016). Despite the normative expectation that community foundations should be more responsive to the needs of the communities in which they are embedded, concerns exist that even community foundations are not responsive to the interests of communities of color (Paarlberg et al., 2019). As community foundations face increased pressure to offer more control to individual donors, spurring the growth of donor advised funds (Barman, 2008; Berman, 2015; Carson, 2014; Ostrander, 2007), concerns arise that wealthy donors will increasingly direct their giving through donor-advised funds housed at community foundations to elite interests rather than inclusive community needs (Semuels, 2018). These criticisms put community foundations at the center of discussions about community philanthropy, diversity, and equity.

This study examines the relationship between ethnic-racial diversity and contributions to donor-advised funds held by community foundations. While diversity is associated with positive cultural and economic benefits (Putnam, 2007), a growing body of research across disciplines suggests that ethnic and racial diversity dampens not only government funded public goods (Alesina, Baqir, \& Easterly, 1999; Poterba, 1997) but also private contributions to public goods 
(Miguel \& Gugerty, 2005; Okten \& Osili, 2004; Andreoni et al., 2016) and voluntary

participation (Alesina \& La Ferrara, 2000; Rotolo \& Wilson, 2012). Prior research offers several theoretical explanations underlying this negative association. Individuals in more diverse communities may prefer different types of public goods (Alesina et al., 1999), and may be less willing to contribute resources to benefit others who are different from their own identity groups (Vigdor, 2004). Compared to homogenous communities, diverse communities also lack norms and strategies to encourage and enforce cooperation across groups (Habyarimana et al, 2007). The theoretical concepts that support a negative relationship between diversity and private support for public goods raises the question whether it is the same for contributions to DAFs. A donor-advised fund (DAF) is a giving vehicle established at a public charity, such as a community foundation, that allows its donor to retain control over the grant distribution from the fund (Berman, 2015; Philipp \& Mazany, 2015). Unlike general contributions to a community foundation that are intended to be redistributed at the discretion of the foundation to respond to collective community needs, DAFs allow donors to redistribute their gifts based upon individual preferences and target their grants to groups with which they identify. Therefore, we argue that although community diversity has been found to reduce charitable giving, contributions to DAFs will be higher in more racially diverse communities as donors increasingly seek to retain control over their charitable gifts (Barman, 2008; Ostrander, 2007).

Drawing community foundation financial data from Form 990 reports to the Internal Revenue Service (IRS) and community characteristics data from the Census Bureau, we test the relationship between community ethnic-racial diversity and contributions to community foundations. Our analyses separate the existence of DAFs from the contributions to DAFs, as well as distinguish between two different types of contributions - general contributions 
controlled by an organization and contributions to DAFs controlled by donors. This design offers two advantages. First, the fundraising and grantmaking of community foundations are geographically bounded, which allows us to link contributions to community foundations with the characteristics of the communities they serve. Second, the focus on community foundations also offers a natural test within organizations - the comparison between contributions to DAFs and contributions for general purposes. More importantly, the tension between a community foundation's focus on collective community needs and DAF donors' personal preferences that guide the distribution of their gifts provides a unique setting to observe resource development in contextually-embedded community philanthropy. Our findings confirm that greater ethnic and racial diversity is significantly associated with higher levels of contributions to DAFs sponsored by community foundations, but not for general contributions or the likelihood of sponsoring DAFs.

This study makes both theoretical and practical contributions. First, it adds to the growing research on diversity and private provision of public goods by focusing on contributions to DAFs, which has grown rapidly in recent years (National Philanthropic Trust (NPT), 2019) and has the potential to change the face of community philanthropy (Colinvaux, 2018; Daniels \& Lindsay, 2016). We present empirical evidence that is different from the traditional wisdom established in this literature - contributions to DAFs hosted by community foundations increase as community ethnic and racial diversity increases. Although we do not directly test the underlying mechanisms, the finding is consistent with the theories that diversity affects public goods provision through heterogenous individual preferences and in-group bias.

Second, the study also contributes to the understanding of the relationship between philanthropy and its context. The vast literature on charitable giving has generally explained 
voluntary contributions to nonprofits from both organizational (Okten \& Weisbrod, 2000;

Tinkelman \& Mankaney, 2007) and individual levels (Bekkers \& Wiepking, 2011). However, we show that philanthropy is a social act, which is embedded in place, and the racial structure of a place is a key predictor of whether and how resources are voluntarily redistributed.

Lastly, the study provides practical implications for the role of private philanthropy in local public policy. Our finding corroborates the debate on the tension that exists in community foundations between local resource dependence and donor control of grantmaking. It provides implications for the contextually embedded fundraising strategies of community philanthropy and helps understand the potential impact of adopting donor control by community foundations and their role in local governance.

The rest of the paper will proceed as follows. We first review the history of DAFs and the contemporary challenges surrounding DAFs in the community foundation field. We then discuss the literature on diversity and public goods provision and present our hypotheses. Next, we describe data and method. Finally, we present the descriptive and regression results, followed by discussions and concluding thoughts.

\section{Background on Donor-Advised Funds}

A donor-advised fund is a philanthropic giving vehicle administered by a charitable sponsor charity (Colinvaux, 2017; NPT, 2019). A donor first establishes an account by making tax-deductible contributions to the sponsor and then recommends grants to their preferred charities from the account, which is managed by the sponsor for a fee. There are generally three types of DAF sponsors, including community foundations with a geographic focus, single-issue charities for a specific cause (e.g. Jewish Federations, universities), and national sponsors affiliated with financial institutions (e.g. Fidelity Charitable Gift Fund, Schwab Charitable, 
Vanguard Charitable Endowment). Community foundations are the most common type of DAF sponsors. Out of about 1000 DAF sponsoring charities tracked by the National Philanthropic Trust since 2007 , about $60 \%$ are community foundations, which also have higher average fund size (nearly half million dollars) than other types of sponsors (NPT, 2019).

With the establishment of the Cleveland Foundation in 1914 and the subsequent spread of community foundations across the country, upper middle class and wealthy donors, had an alternative to private foundations as a means to leave a chartable legacy to their community (Hammack, 1989). The early Cleveland community foundation model stressed the strategy of soliciting bequests, whose later distribution would be guided by knowledgeable community leaders, a professional approach to distribution decisions (Berman, 2015). As Hammack notes, “...those who commit unrestricted funds to a community foundation agree to support purposes they cannot know, purposes that are certain to be changed in ways they cannot anticipate by a group of people whose identities and commitments are also certain to change" $(1989, \mathrm{p} .24)$.

The New York Community Trust pioneered a new model, the "donor-advised fund" in 1931 (Berman, 2015; Colinvaux, 2017; Hammack, 1989). This model allowed living donors to actively engage with and direct their donations. While the New York Community Trust set the stage for DAFs, the changes in tax law further shaped the development of DAFs. In particular, the 1969 Tax Reform Act distinguished public charities from private foundations, requiring the latter, but not the former, to meet a minimum annual payout standard and pay excise tax on certain investment income. By giving preferential tax treatment to public charities, the 1969 Act provided potential incentives for wealthy donors to establish funds in public charities rather than having their own private foundations (Berman, 2015). Through a private-letter ruling to the attorney for the Cleveland Jewish Federations, the IRS allowed an informal system of donor 
control, in which donors could establish funds in public charities while maintaining the right of advising the distribution of their funds. As the practice of DAFs continued to expand within community foundations and Jewish Federations in the latter decades of the $20^{\text {th }}$ century, DAFs served as an efficient alternative to the establishment of private foundations.

While DAFs originated in charitable public foundations, later legal rulings have opened the door for national sponsors, many of the largest being either charitable arms of commercial financial institutions or single-issue sponsors (Colinvaux, 2017). The number and financial assets of DAFs have seen rapid growth in recent years. Based on data from 989 charitable sponsors between 2014 and 2018, the NPT (2019) reports that both contributions to DAFs (over \$37 billion) and grants from DAFs (over \$23 billion) in 2018 have almost doubled the amounts in 2014. Particularly, contributions to DAFs have grown much faster than other forms of individual giving (Collins et al., 2018).

The explosive growth of DAFs has generated increasing concerns and calls for more regulation (Andreoni, 2018; Colinvaux, 2017; Madoff, 2016). Criticisms exist that DAFs warehouse the giving of elite donors due to the lack of mandated payout restrictions (Collins et al., 2018; Heist \& Vance-McMullen, 2019). Particularly, there are concerns that DAFs compromise the place-based identity of community foundations, pulling them into a more donorfocused, national model (Colinvaux, 2018). Because DAFs allow donors to retain discretionary control over grantmaking, DAFs limit community foundation's ability to direct funding and may challenge community foundations' strategic roles in grantmaking.

\section{Literature and Hypotheses}

Despite discussions that place no longer matters in the $21^{\text {st }}$ century, philanthropic resources are unequally distributed across places (Ashley, 2014). These differences exist not 
because organizations self-select into place, but because place shapes organizational strategies and outcomes. Local social structure shapes the capacity of organizations to bring individuals together and contribute resources to support collective action (Sampson \& Graif, 2009). Place is more than the aggregated characteristics of individuals. Instead, place represents opportunity structures and social structures that both support and constrain collective action. One of the most important social structures is ethnic and racial diversity. In the following, we will first review the theoretical explanations of the relationship between diversity and public goods provision, and then discuss the implications for contributions to community foundations and present our hypotheses.

\section{Literature on Diversity and Public Goods Provision}

With the exception of demand heterogeneity theory, which predicts that voluntary contributions will increase in diverse communities when government fails to meet the demands of diverse populations for quasi-public goods (Weisbrod, 1986), a large body of research across social science disciplines consistently finds that ethnical and racial diversity is negatively associated with public good provision and collective action both within the U.S. and across countries (Alesina \& La Ferrara, 2005; Stichnoth \& Van der Straeten, 2013). For example, studies find that more diverse communities spend less on public education (Poterba, 1997; Goldin \& Katz, 1999), roads, and other public goods (Alesina et al.,1999). Individuals in diverse communities prefer lower levels of social benefits (Dahlberg, Edmark, \& Lundqvist, 2012), are less likely to complete Census forms (Vigdor, 2004), and participate less in social activities (Alesina \& La Ferrara, 2000) and volunteer less (Rotolo \& Wilson, 2012). Research specific to private philanthropy also finds that as ethnic and racial heterogeneity increases, charitable donations decrease (Okten \& Osili, 2004; Andreoni et al., 2016; Paarlberg \& Zuhlke, 2019). 
The literature provides several theoretical explanations for the negative relationship diversity and public good provision. First, collective action is more difficult to secure in diverse communities due to the difficulty to reconcile heterogenous individual preferences for public goods, as well as the lack of resources and strategies available for collective action. Different groups in diverse communities may prefer different types of public goods, and compromises are often difficult or costly to reach, leading to lower provision of the goods (Alesina et al., 1999). Particularly, since many American communities are highly segregated, residents may have fewer opportunities to reach agreements on differing preferences (Trounstine, 2016). Even organizations, which attract similar-minded participants and are homogenous by nature, become isolated in diverse communities and are less likely to coalesce around the collective issues of a larger community (Longhofer, Negro, \& Roberts, 2019).

Moreover, diverse communities have a smaller toolbox of strategies available to promote and enforce collective action (Habyarimana et al., 2007). Homogenous communities can draw upon a "common cultural material" (e.g. language, experience) that makes it easier for residents to work together, and they can also rely on shared networks to identify contributors, encourage cooperation, and punish non-cooperators. In contrast, diverse communities do not have shared norms of reciprocity that encourage broad-based participation (Poteete \& Ostrom, 2004) and they face higher transaction costs of securing voluntary participation (Okten \& Osili, 2004). While homogenous communities are better able to enforce social sanctioning of non-contributors (Habyarimana et al, 2007), the inability to impose social sanctions in diverse communities leads to collective action failures (Miguel \& Gugerty, 2005).

Second, individuals may be less willing to contribute resources to benefit others who are different from their own identity groups. Social identity theory suggests that individuals attribute 
positive utility to the welfare of in-group members, but little or negative utility to that of outgroup members (Tajfel et al., 1971). As Habyarimana et al (2007, p. 710) describe, “...community members may be willing to bear the cost of providing public goods if they believe that most of the beneficiaries will be "co-ethnics." Similarly, Cutler, Elmendorf, and Zeckhauser (1993, p. 180) find that people have "discriminatory community preferences," where they only "care about the welfare of others within their ethnic community." Although we generally assume that philanthropy is "other serving", Ben-Ner (2018, p.4) observes "most giving by the vast majority of donors is directed to members of donors' in-group defined in terms of religion, ethnicity or cultural preferences."

Empirical studies on charitable giving provide some evidence consistent with this explanation. For example, Fong and Luttmer's experiment (2009) shows that respondents give more when they identify with the racial backgrounds of Hurricane Katrina victims. Hungerman (2008) find that all-white congregations spend less on charitable activities as the share of black residents in the community increases. Similarly, Dimitrova-Grajzl, et al. (2016) also finds evidence that religious giving is driven by preferences for racial group affinity, with an increase in racial diversity associated with a decrease in religious giving, particularly in urban areas. In sum, individuals in diverse communities may be less willing to redistribute resources when they perceive that their beneficiaries are less likely to resemble them.

\section{Hypotheses for Community Foundations and DAFs}

Diversity may also affect general contributions to community foundations in a similar manner. Community foundations are anchor institutions which by virtue of their mission and reliance on local financial and social resources are tied to a defined geographic location (Perry \& Mazany, 2014). Because of this heavy reliance on financial and social resources of their 
communities, racial and ethnic diversity may shape the strategy and revenue structure of community foundations. One of the fundamental legacies of community foundations is that they represented a way for middle- and upper-class individuals to redistribute resources to respond to the current and future collective needs of their geographic communities (Hammack, 1989; Perry \& Mazany, 2014). Unlike private foundations, the mission of community foundations is “...the community, not restricted to the interests of any individual grant recipient, not limited to the interests of an individual donor..." (Perry \& Mazany, 2014, p. 5). This communal role provides legal and moral legitimacy for community foundations as a public institution (Colinvaux, 2018). This leads us to posit that "general" contributions to community foundations (those that are not directed towards DAFs) are potentially "other benefitting" and resemble support for the public good. Based on the literature on the negative association between diversity and private contributions to public goods, we posit that:

Hypothesis 1: Community ethnic and racial diversity is negatively associated with nonDAF contributions to community foundations.

On the other hand, we argue that contributions to DAFs at community foundations will increase as ethnic and racial diversity increases. Andreoni et al. (2016) postulate that when individuals in diverse communities feel less connected across groups but more connected within their own identity groups, they may substitute private contributions for public-funded public goods as a way to target benefits to their own groups, which would then increase private contributions. In this case, DAFs may be more well-positioned for the substitution than general contributions. Contributions to DAFs represents the preference of donors to retain control over the redistribution of their gifts (supported by the existence and promotion of DAF vehicles within their local community foundation). Like the concept of "residential sorting", DAFs 
provide a mechanism for philanthropic sorting. In the face of heterogeneous preferences, DAFs provide opportunities for donors who have decided to use a community foundation as a vehicle for their philanthropy to redistribute their contributions toward their preferred public goods. As to in-group bias in diverse communities, DAFs allows individuals to target benefits to their ingroup members and enhance the status of their own group. Therefore, we posit that:

Hypothesis 2: Community ethnic and racial diversity is positively associated with DAF contributions to community foundations.

\section{Data and Methods}

\section{Data}

This study draws data from multiple sources. First, the organizational-level data are from the IRS Forms 990 filed electronically by 501(c)(3) public charities. Donor-advised fund information is available via Schedule D Part I and other organizational information is from the core file. Second, the community-level socio-economic variables, including ethnic and racial characteristics, come from the 2011-2015 U.S. Census Bureau American Community Survey 5year estimates. Third, the county-level social capital variable is from the Penn State University Northeast Regional Center for Rural Development (Rupasingha, Goetz, \& Freshwater, 2006, with updates). Due to limited years for the DAF information and little variation in the independent and control variables, we use a cross-sectional rather than a panel study. Our final sample includes 738 community foundations (549 DAF sponsors and 189 non-DAF sponsors)

that e-filed Forms 990 in 2013 and 2014 and had complete information for all variables. ${ }^{1}$ The list of community foundations was identified by a search of institutional listings provided by the Council of Foundations and Candid and verified through webpages and tax reports.

\section{Empirical Models and Variables}


Our research focuses on how a community foundation's contributions revenuecontributions for general purposes and contributions to DAFs—is related to community characteristics. Specifically, our three-step analyses examine the relationship between community ethnic-racial diversity and the probability of sponsoring DAFs by a community foundation, as well as the relationship between diversity and two different types of contributions to community foundations, controlling for various community- and organizational-level characteristics. We first introduce each estimation and then describe the variables in detail.

First, not all community foundations choose to sponsor DAFs and receive contributions to DAFs. Therefore, we begin with examining if ethnic-racial diversity is associated with the probability of sponsoring $D A F s$ by a community foundation using a logit regression. This analysis captures an organization's strategic choice of being a DAF sponsor in relation to diversity and other community- and organizational-level factors.

Second, to compare with contributions to DAFs, we examine the relationship between ethnic-racial diversity and general contributions that are not designated to DAFs received by a community foundation (Hypothesis 1). Although all community foundations rely on donations, some may not receive donations every year. Therefore, we use tobit regressions with the dependent variable left-censored at 0 and separately analyze general contributions to DAF sponsors and non-DAF sponsors.

Third, our main analyses examine the relationship between community ethnic-racial diversity and contributions to DAFs for DAF sponsors using OLS regressions (Hypothesis 2). This setup represents a distinction between the organizational decision to host a DAF and the aggregate decision of donors to direct their giving to DAFs. While organizational actors make the strategic decision whether or not to sponsor a DAF, contributions to DAFs represent donors' 
preferences and reflect the aggregate level of control that donors prefer to exercise over their contributions to a community organization.

Dependent variables. The dependent variable in the DAF participation estimation is a dummy variable indicating sponsoring DAFs or not. Specifically, it is coded as 1 if an organization reported having DAFs on Form 990 core file (Part IV, Line 6) and also reported any DAF information on Schedule D Part I.

The dependent variable in the general contribution estimation is the log of non-DAF contributions received by a community foundation. A proxy variable for non-DAF contributions is obtained by subtracting DAF contributions from total contributions (Part IV, Line 6). ${ }^{2}$ Note that due to data availability, we are not able to separate between contributions from individual donors and grants given by government units, foundations, and other organizations. Nonetheless, this should have minimal influence on our results because community foundations are mostly dependent on donations from the general public.

The dependent variable in the DAF contribution estimation is the log of contributions to DAFs received by a DAF sponsor (Schedule D, Part I, Line 2). All the dependent variables were measured in 2014, the latest year available at the time of this study that allows for the largest sample size. Because the dependent variables were observed in 2014, we use the lagged observations of independent and control variables (except for organizational age and region), discussed as follows (see variable definitions in Table S1, Supplemental Materials).

Independent variable. Our independent variable is ethnic-racial diversity at the county level. It is measured by the fragmentation index (FI) that is widely used in prior research (Andreoni et al., 2016; E. Graddy \& Wang, 2009; Okten \& Osili, 2004; Rupasingha et al., 2006). 
The FI is constructed using the share of each ethnic-racial group in counties served by a community foundation:

$$
F I=1-\sum_{k=1}^{7}\left(\text { Share }_{k}\right)^{2},
$$

where Share $_{k}$ includes the share of population in each county identifying as Hispanic or Latino, non-Hispanic White alone, non-Hispanic Black or African American alone, non-Hispanic Asian alone, non-Hispanic Native Hawaiian and Pacific Islander alone, non-Hispanic American Indian and Alaska Native alone, and Other (other race alone or more than one race). The FI ranges from zero to one, with zero indicating that a county's population is composed of one group (the most homogeneous) and one indicating that it is divided equally among all the groups (the most heterogenous). Note that about 28 percent $(\mathrm{N}=208)$ of the sample served more than one county. For these organizations, the FI is constructed using the aggregated data on the total population and population shares of each ethnic-racial group across all counties served.

Community-level characteristics. We control for various county-level factors that may affect charitable donations, including social capital and sociodemographic characteristics.

Social capital is generally referred to as the social networks among individuals, as well as the shared norms and values among group members that in turn facilitate trust, reciprocity, cooperation and collective action (Fukuyama, 1995; Putnam, 2000, 2007). Empirical research has confirmed a positive relationship between social capital and individual charitable giving, among other forms of generosity (Brooks, 2005; Brown \& Ferris, 2007; Herzog \& Yang, 2018). Relevant to our study, Graddy and Wang (2008) find community level social capital, specifically social trust, is positively related to per-capita giving to community foundations. Therefore, we include county-level social capital in the model. 
We use the county-level social capital index in $2009^{3}$ developed by Rupasingha, Goetz, and Freshwater (2006). The index is created using principal component analysis of four factors at the county level - the number of associations per 1000 people, the number of nonprofit organizations (excluding those with an international approach) per 10,000 people, voter turnout rate, and census response rate, with the first principal component interpreted as the social capital index. This approach is based on the argument that "social capital manifests itself in individuals through their participation in associational activities" (Rupasingha et al., 2006, p.88). Although this index includes no measures of individual attitudes or behavior, Putnam (2007) found it to be strongly correlated with an independent survey-based measure of social trust.

Sociodemographic characteristics. Following prior literature (e.g. Andreoni et al., 2016; Graddy \& Wang, 2008; Okten \& Osili, 2004), we control for county-level sociodemographic variables that may affect charitable donations, including the log of median household income, income inequality (mean income/median income), education attainment (percentage of having a college degree or higher), median county age and its quadratic form, the log of total population served, and service areas (the square root of the number of counties served). Except for population and service areas, the county-level covariates represent the average values across all counties when an organization serves more than one county.

The characteristics of residents affects their capacity to give and their propensity to give to local organizations (Graddy \& Wang, 2009). Income is expected to be positively associated with the capacity to give, while income inequality is found to be negatively associated with the probability of giving (Okten \& Osili, 2004). Education is positively associated with increased awareness of public issues and social connections necessary to become engaged (Brown \& Ferris, 2007). Age is a life cycle indicator of community involvement and the capacity to 
contribute to community needs (Graddy \& Wang, 2009). Additionally, consistent with notions of community integration, we expect that a larger population size dampens social cohesion and a sense of connection to place (Grønbjerg \& Paarlberg, 2001). Finally, the total number of counties served by a community foundation indicates the size of the organization's donor pool.

Organizational-level characteristics. We include several organizational-level factors that prior literature has found to be significant determinants of donations to nonprofits, including information available to donors, efficiency, and reputation.

First, we control for fundraising expenses (in natural log), assuming that donations to a nonprofit depend on its fundraising efforts in the prior year. Fundraising expenses are often used as a proxy for the information that an organization makes available to its potential donors and found to be positively associated with donations (Frumkin \& Kim, 2001; Tinkelman, 1999). Prior research suggests that fundraising expenses may increase contributions directly by reducing information costs for donors while decreasing contributions indirectly by increasing donors' perceived price of giving, but the net effect is generally positive (Okten \& Weisbrod, 2000; Tinkelman \& Mankaney, 2007; Weisbrod \& Dominguez, 1986).

Second, we include program expense ratio (i.e. program expenses divided by total expenses) as a proxy for perceived efficiency that may affect donations to an organization. Studies show that an organization's operational efficiency is one of the most important factors used by donors (Parsons, 2003; Trussel \& Parsons, 2007), reporting a significant association between donations and various expense ratios (e.g. Posnett and Sandler 1989; Greenlee \& Brown, 1999; Roberts, Smith, \& Taranto, 2006; Tinkelman \& Mankaney, 2007).

In addition, we control for an organization's age and its quadratic form, as well as size, measured as the log of total assets. Both age and size signal an organization's reputation and 
quality, which may affect its fundraising productivity (Trussel \& Parsons, 2007). Prior research reports mixed findings on the relation between age and donations (e.g. Weisbrod \& Dominguez, 1986; Posnett \& Sandler, 1989; Tinkelman, 1999; Okten \& Weisbrod, 2000; Harris \& Neely, 2016). As to DAFs, older community foundations are likely to pre-date the contemporary explosion of DAFs, and younger organizations are more likely to adopt a donor orientation in order to build endowments as part of the life cycle process of development (Graddy \& Morgan, 2006). On the other hand, organizations need to have the capacity to manage DAFs. We therefore posit that younger organizations are more likely establish donor-advised funds, but older and larger organizations with more reputational capital and higher capacity are more likely to be successful in generating contributions to DAFs.

Finally, there may be regional differences in the distribution of DAF sponsors as there are regional differences in the historical development of the community foundations (Hammack, 1989). Schneider (1996) posits that regions have distinct philanthropic cultures as patterns of settlement and immigration shaped regional perceptions of the role of government and philanthropy in meeting local needs. Consistent with the "civic culture" of the region, many Midwest community foundations, following the model of the Cleveland Community Foundation, took a community centered approach to focus on studying and responding to community needs. In contrast, community foundations in the Northeast often developed as an arm of individual philanthropy (Hammack, 1989). Therefore, we include geographical region to control for the history and tradition that may influence a community foundation's tendency to engage in DAFs.

\section{Descriptive Results}

Table 1 reports the sample summary statistics by DAF sponsors $(\mathrm{n}=549)$ and non-DAF sponsors $(\mathrm{n}=189)$. Nearly 75 percent of the community foundations in our sample sponsored 
DAFs and received contributions to DAFs in 2014. Among DAF sponsors, the average contributions to DAFs were about $\$ 8.68$ million in 2014 ( $\mathrm{SD}=\$ 83.7 \mathrm{M})$. Both non-DAF contributions (Mean $=\$ 4.03 \mathrm{M}, \mathrm{SD}=\$ 11.30 \mathrm{M}$ ) and total contributions to $\mathrm{DAF}$ sponsors (Mean $=\$ 12.70 \mathrm{M}, \mathrm{SD}=\$ 85.50 \mathrm{M})$ were significantly higher than contributions to non-DAF sponsors (Mean $=\$ 0.43 \mathrm{M}, \mathrm{SD}=\$ 1.71 \mathrm{M})$. The high standard deviations suggested that the level of contributions was highly skewed across organizations.

The sample of DAF sponsors and non-DAF sponsors shared similar community-level characteristics. However, DAF sponsors (Mean=12.25, $\mathrm{SD}=1.47$ ), on average, served a significantly larger population size than non-DAF sponsors (Mean=11.53, $\mathrm{SD}=1.86$ ). Although the majority of the sample $(72 \%, n=530)$ served only one county, DAF sponsors (Mean=3.65, $\mathrm{SD}=7.45$ ) served a significantly higher average number of counties than non-DAF sponsors (Mean=1.20, $\mathrm{SD}=0.88$ ). In addition, the standardized social capital index in the counties of DAF sponsors (Mean=-0.13, $\mathrm{SD}=0.89$ ) was slightly lower than that of non-DAF sponsors (Mean=0.01, $\mathrm{SD}=1.26$ ), with the difference being marginally significant.

DAF sponsors and non-DAF sponsors differed significantly in their organizational characteristics. DAF sponsors spent significantly more on fundraising (Mean=3.60, $\mathrm{SD}=4.98$ ) than non-DAF sponsors (Mean=2.37, $\mathrm{SD}=4.27$ ). $\mathrm{DAF}$ sponsors also had a significantly higher average program expense ratio (Mean $=0.66, \mathrm{SD}=0.19$ ) than non-DAF sponsors (Mean $=0.58$, $\mathrm{SD}=0.34$ ). On average, $\mathrm{DAF}$ sponsors (Mean $=28, \mathrm{SD}=16$ ) were older organizations than nonDAF sponsors (Mean=24, $\mathrm{SD}=13$ ). $\mathrm{DAF}$ sponsors were also larger organizations with significantly higher total assets (Mean=16.94, $\mathrm{SD}=1.67$ ), compared to those without DAFs (Mean=14.20, SD=1.44). Finally, there was a significant difference in the regional distribution of DAF sponsors and non-DAF sponsors. Among DAF sponsors, the Midwest had the highest 
number of community foundations sponsoring DAFs while the Northeast had the smallest number of DAF sponsors. Across regions, community foundations in the West are less likely to sponsor DAFs (65.5\%) than those in the South $(80.5 \%)$.

[Table 1]

\section{Regression results}

\section{The Probability of Sponsoring DAFs}

We started the analysis by examining the factors associated with DAF sponsorship status. Table 2 reports results from the logistic regressions on the probability of sponsoring DAFs by a community foundation. Most of the community-level variables, including the ethnic-racial diversity index, were not significant. However, the average marginal effect of service areas was significantly positive, indicating organizations serving more counties had a higher probability of sponsoring DAFs. Most of the organizational variables were significant. Specifically, fundraising expenses and total assets were significantly and positively associated with the likelihood of holding DAFs. The significantly negative coefficient on organizational age and positive coefficient on age squared suggested a non-linear effect of organizational age on the probability of sponsoring DAFs.

[Table 2]

\section{Diversity and Non-DAF Contributions}

To test Hypothesis 1, we used tobit regressions to estimate the relationship between diversity and non-DAF contributions to DAF sponsors and non-DAF sponsors respectively, controlling for community- and organizational level characteristics. Among DAF sponsors (Table 3 Column (1)), the coefficient on ethnic-racial diversity was non-significant. The only significant factors were service areas, fundraising expenses, and total assets. This suggested that 
larger DAF sponsors that served more counties and spent more on fundraising activities received more general contributions. For the small sample of non-DAF sponsors (Table 3 Column (2)), the coefficient on the diversity index, although negative, was non-significant. The number of service areas was significantly positive, but most of the community- and organizational-level variables were non-significant. Overall, we did not find support for Hypothesis 1.

\section{[Table 3]}

\section{Diversity and Contributions to DAFs}

Main analysis. To test Hypothesis 2, we used OLS regressions to estimate the relationship between ethnic-racial diversity and contributions to DAFs (Table 4). The first two columns of Table 4 report results based on all DAF sponsors. The coefficient on the diversity index was significantly positive, even after controlling for various covariates. Everything else being equal, contributions to DAFs increases by about $20 \%$ with every 0.1 unit increase in ethnic-racial diversity (on a scale of 0 to 1 ), supporting H2. Because we controlled for income inequality, the result on ethnic-racial diversity was not driven by income inequality.

Turning to the covariates, the number of service areas continued to be a significantly positive factor, indicating that organizations serving more areas received more donations to DAFs. The social capital index was positively related to contributions to DAFs, but the result was only marginally significant. Fundraising expenses, program expense ratio, and total assets were all significantly and positively associated with contributions to DAFs, while organizational age showed a non-linear relationship. Finally, compared to those located in Midwest, DAF sponsors in the South and the West received more donations to their DAFs.

[Table 4] 
Robustness checks. One might argue that ethnic-racial diversity increases with a higher number of service areas and the observed relationship between diversity and contributions to DAFs is driven by those serving multiple counties. As a robustness check, we further conducted analyses by DAF sponsor serving only one county $(\mathrm{N}=357)$ and those serving more than one county (N=192). Shown in Table 4 Column (2), for the DAF sponsors serving only one county, the coefficient on ethnic-racial diversity was still significantly positive, with an improved statistical significance and larger magnitude. On the other hand, for those serving more than one county (Table 4 Column (3)), the coefficient on diversity became non-significant. Overall, the result on the positive relationship between diversity and contributions to DAFs was robust for those serving one county, even when controlling for income inequality and other covariates.

A moderately heterogenous community may be highly polarized if it is dominated by two groups. Therefore, to test the robustness of our models, we follow Andreoni et al. (2016) to include an alternative analysis, in which we further explored the relationship between ethnicracial polarization and contributions to DAFs, using an alternative measure that captures polarization, namely the RQ index (Andreoni et al., 2016; Montalvo \& Reynal-Querol, 2002). It is defined as:

$$
R Q=1-\sum_{k=1}^{7}\left(\frac{0.5-\text { Share }_{k}}{0.5}\right)^{2} \text { Share }_{k}
$$

Unlike the FI, the RQ index takes the maximum value when the community population is equally divided by two groups. The RQ and FI are highly correlated at the lower values of the FI, that is, a relatively more homogenous community also has little polarization. However, they are not correlated at the middle values of the FI, as a moderately heterogenous community may be highly polarized if it is dominated by two groups. The two indices are negatively correlated at the higher values of the FI, indicating that a highly heterogenous community may become less 
polarized. The results using the polarization index were very similar to those using the diversity index (see Table S2, Supplemental Materials).

\section{Discussion}

Empirical research generally reports a negative relationship between diversity and private contributions to public goods. The theoretical explanations for this negative relationship include the difficulty to resolve diverging individual preferences for the types of public goods to be funded in more diverse communities, the lack of shared norms and strategies that encourage and enforce collective action across groups, as well as individuals' unwillingness to contribute to public goods that accrue benefits to out-groups. These factors should also apply to general contributions to community foundations for the collective needs of specific geographic communities. However, it is not clear whether it is the same for contributions to DAFs, which allow donors to retain advisory control over the distribution of their donated funds. DAFs provide an alternative mechanism that allows donors to redistribute their gifts according to their personal preferences and target benefits to their in-groups, potentially overcoming the common barriers in securing private contributions to public goods. Therefore, we analyzed the relationship between diversity and contributions to DAFs housed at community foundations, distinguished from general contributions to community foundations.

We find that contributions to DAFs hosted by community foundations increase as community ethnic-racial diversity increases, even when controlling for various community and organizational characteristics. The finding provides indirect support for the theoretical mechanisms underlying the relationship between diversity and contributions to the public good. It also suggests that future research should try to differentiate between the types of charitable contributions that allow for donor control over fund distribution and those at the discretion of 
public foundations. On the other hand, we did not find a significant relationship between diversity and the likelihood of being a DAF sponsor, or between diversity and general donations to community foundations. Although it does not support Hypothesis 1, the finding is consistent with the finding on community foundations by Graddy and Wang (2009). The result may reflect that general contributions to community foundations often emerge from bequests and represent historical community conditions.

The findings have important implications for research on the context of philanthropy, particularly the practice of community-based institutional philanthropy. First, unlike much research on charitable giving that focuses on individual and organizational levels, our study shows that philanthropy is a social act shaped by place-based characteristics. On the one hand, the decision to sponsor a DAF is an organizational decision mainly shaped by an organization's capacity rather than community characteristics. Larger community foundations that invest more on fundraising and serve more counties (thus a potentially larger donor pool) are more likely to sponsor DAFs. On the other hand, contributions to DAFs appear to reflect the aggregate decision of donors to retain control over their giving to the local community foundations, which is shaped by not only organizational but also community characteristics, particularly ethnic-racial diversity.

Our study cannot directly uncover the motivations of individual donors to DAFs and we have artificially constrained donor choices to two vehicles, general contributions versus donordirected contributions at community foundations. We acknowledge that donors have opportunities to direct their giving to other organizations within and outside their communities. In reality, donors may use other giving vehicles, such as giving circles or field of interest funds hosted by community foundations. They also have the option to directly give to nonprofits in the 
community. It is likely that in more diverse communities, donors may forego community foundations entirely and instead either not donate or direct their funds to specific charities that reflect their interests and preferences. Consistent with the growing body of research that has examined the relationship between various dimensions of diversity and the provision of public goods and other forms of cooperative behavior, additional research is needed to examine the relationship between philanthropy and community context.

Second, while we are unable to identify the motivations of individual donors, our findings suggest that DAFs may represent a way to avoid the challenges and conflicts inherent in collective action in diverse communities. As community diversity increases, donors may be more likely to prefer to exercise advisement and direct their contributions to groups and issues with which they identify. However, donor values may not align with the preferences of community foundations, challenging the legitimacy and strategic intent of the organizations. This raises questions about community foundations' capacity to financially support public goods in diverse communities. As the U.S. continues to deal with issues of racial and economic justice, these findings have important implications for community foundations' capacity to support and lead strategic efforts to advance equity in community grantmaking.

To the best of our knowledge, this is the first study that examines the relationship between ethnic-racial diversity and contributions to general and donor directed funds. It also adds to the very limited research on DAFs. Taking advantage of the newly available data on DAFs, we are able to separately analyze contributions to DAFs and general donations not designated to DAFs. Because there are limited years' data available and little variation in community- and organizational level characteristics, we used a cross-sectional analysis that only examined contributions in a single year. We controlled for a range of covariates, but the 
possibility of omitted variables remains. Like all research relying on Form 990 e-filer database, there are concerns about sample representativeness as the data are from organizations choosing to file electronically, which tend to be larger organizations. The issue might be mitigated in our study as DAF sponsors are usually larger than non-DAF sponsors. Nonetheless, as the IRS starts requiring mandatory electronic filing by all eligible nonprofits, we recommend future research to reexamine this research question through panel data analysis using more recent data. In addition, while our analyses focus on the aggregate contributions at the organizational level, future DAF research may link individual-level contributions and ethnic-racial identity with community diversity. Beyond the focus on DAFs, future research may further explore whether a positive association exists for other types of contributions that allow for donor control in practice, such as giving circles. Experiments may also examine the mechanisms by varying the levels of donor control in grant making and see if it lessens the collective action issues.

\section{Conclusion}

As local public governance becomes more reliant on private philanthropy, understanding the complex relationships between community ethnic-racial diversity and philanthropy becomes critical. Our study contributes to the body of empirical research on the relationship between diversity and private contributions to public goods. Different from prior research, our analyses distinguish general contributions, which are granted by a community foundation on behalf of the community's collective interests, from contributions to the foundation's DAFs, which allow donors to retain control over their fund distribution based on their personal preferences. While prior empirical research generally reports a negative association between community diversity and private support for the public good, we find that community foundations in more ethnically and racially diverse communities received more contributions to DAFs. Although sponsoring 
DAFs seems to be an effective tool of raising overall private contributions in diverse communities in response to either conflicts or collective action issues, concerns exist as to whether the increased contributions to DAFs will be distributed based on aligned community collective interests and donors' personal preferences. This further raises policy concerns, especially in diverse communities, on community foundations' capacity to financially support public goods provision and their role in social equity.

\section{Notes:}

${ }^{1}$ Organizations that reported having DAFs but did not report any fund information or contribution information on Schedule D were excluded from the sample. We also excluded the terminated organizations and those with low assets (0-1 dollar).

${ }^{2}$ There were 28 organizations that reported higher contributions to DAF than total contributions, and thus negative non-DAF contributions. They were excluded from the analysis on non-DAF contributions.

${ }^{3}$ Besides 2014, the latest available social capital index is in 2009. Nonetheless, the index of 2014 and 2009 are highly correlated $(r=.92)$, indicating that the county-level social capital tends to stay stable in recent years. 


\section{References}

Alesina, A., Baqir, R., \& Easterly, W. (1999). Public goods and ethnic divisions. Quarterly Journal of Economics, 11(4), 1243-1284.

Alesina, A., La Ferrara, E. (2000). Participation in heterogeneous communities. Quarterly Journal of Economics, 115(3): 847-904.

Alesina, A., La Ferrara E. (2005). Ethnic diversity and economic performance. Journal of Economic Literature, 43(3): 762-800.

Andreoni, J. (2018). The Benefits and Costs of Donor-Advised Funds. Tax Policy and the Economy, 32(1), 1-44.

Andreoni, J., Payne, A., Smith, J., \& Karp, D. (2016). Diversity and donations: The effect of religious and ethnic diversity on charitable giving. Journal of Economic Behavior \& Organization, 128, 47-58.

Ashley, S. R. (2014). Is the Inequality Equitable? An Examination of the Distributive Equity of Philanthropic Grants to Rural Communities. Administration \& Society, 46(6), 684-706.

Barman, E. (2008). With Strings Attached: Nonprofits and the Adoption of Donor Choice. Nonprofit and Voluntary Sector Quarterly, 37(1), 39-56.

Bekkers, R., \& Wiepking, P. (2011). A Literature Review of Empirical Studies of Philanthropy: Eight Mechanisms That Drive Charitable Giving. Nonprofit and Voluntary Sector Quarterly, 40(5), 924-973.

Ben Barge, Collins-Calhoun, B., \& Garcia, E. (2020, August 26). Black funding denied: Community foundation support for Black communities. National Committee For Responsive Philanthropy. http://www.ncrp.org/2020/08/black-funding-denied.html 
Ben-Ner, A. (2018). Is Altruism (Always) Good for Society? The Problem of Particularistic Giving in a Diverse Society. Academy of Management Proceedings, 2018(1), 11625.

Berman, L. (2015). Donor Advised Funds in Historical Perspective. Forum on Philanthropy and the Public Good. https://lawdigitalcommons.bc.edu/philanthropyforum/donoradvised2015/papers/2

Brooks, A. C. (2005). Does Social Capital Make You Generous?. Social Science Quarterly, $86(1), 1-15$.

Brown, E., \& Ferris, J. M. (2007). Social Capital and Philanthropy: An Analysis of the Impact of Social Capital on Individual Giving and Volunteering. Nonprofit and Voluntary Sector Quarterly, 36(1), 85-99.

Carman, J. G. (2001). Community Foundations: A Growing Resource for Community Development. Nonprofit Management and Leadership, 12(1), 7-24.

Carson, E. D. (2014). The Future of Community Foundations. In Here for Good: Community Foundations and the Challenges of the 21st Century (pp. 43-58). Routledge.

Colinvaux, R. (2017). Donor Advised Funds: Charitable Spending Vehicles for 21st Century Philanthropy. Washington Law Review, 92, 39.

Colinvaux, R. (2018). Defending Place-Based Philanthropy by Defining the Community Foundation. Brigham Young University Law Review, 2018(1), 1-56.

Collins, C., Flannery, H., \& Hoxie, J. (2018, July 25). Report: Warehousing Wealth. Institute for Policy Studies. https://ips-dc.org/report-warehousing-wealth/

Cutler, D. M., Elmendorf, D. W., \& Zeckhauser, R. J. (1993). Demographic characteristics and the public bundle. NBER Working Paper, (w4283). 
Dahlberg, M., Edmark, K., \& Lundqvist, H. (2012). Ethnic Diversity and Preferences for Redistribution. Journal of Political Economy, 120(1), 41-76.

Daly, S. (2008). Institutional Innovation in Philanthropy: Community Foundations in the UK. VOLUNTAS: International Journal of Voluntary and Nonprofit Organizations, 19(3), $219-241$.

Daniels, A., \& Lindsay, D. (2016, November). Donor-Advised Funds Reshape the Philanthropy Landscape. 6.

Dimitrova-Grajzl, V., Grajzl, P., Guse, A. J., \& Smith, J. T. (2016). Racial Group Affinity and Religious Giving: Evidence from Congregation-Level Panel Data. The B.E. Journal of Economic Analysis \& Policy, 16(2), 689-725.

Fong, C. M., \& Luttmer, E. F. P. (2009). What Determines Giving to Hurricane Katrina Victims? Experimental Evidence on Racial Group Loyalty. American Economic Journal: Applied Economics, 1(2), 64-87.

Frumkin, P., \& Kim, M. T. (2001). Strategic Positioning and the Financing of Nonprofit Organizations: Is Efficiency Rewarded in the Contributions Marketplace? Public Administration Review, 61(3), 266-275.

Fukuyama, F. (1995). Social Capital and the Global Economy. Foreign Affairs, 74, 89.

Giridharadas, A. (2019). Winners Take All: The Elite Charade of Changing the World. Knopf Doubleday Publishing Group.

Goldin, C., \& Katz, L. F. (1999). Human capital and social capital: the rise of secondary schooling in America, 1910-1940. Journal of interdisciplinary history, 29(4), 683-723.

Graddy, E. A., \& Morgan, D. L. (2006). Community Foundations, Organizational Strategy, and Public Policy. Nonprofit and Voluntary Sector Quarterly, 35(4), 605-630. 
Graddy, E., \& Wang, L. (2009). Community Foundation Development and Social Capital. Nonprofit and Voluntary Sector Quarterly, 38(3), 392-412.

Grønbjerg, K. A., \& Paarlberg, L. (2001). Community Variations in the Size and Scope of the Nonprofit Sector: Theory and Preliminary Findings. Nonprofit and Voluntary Sector Quarterly, 30(4), 684-706.

Habyarimana, J., Humphreys, M., Posner, D. N., \& Weinstein, J. M. (2007). Why Does Ethnic Diversity Undermine Public Goods Provision? The American Political Science Review, 101(4), 709-725.

Hammack, D. C. (1989). Community Foundations: The Delicate Question of Purpose. In $A n$ Agile Servant (pp. 23-50). The Foundation Center.

Heist, H. D., \& Vance-McMullen, D. (2019). Understanding Donor-Advised Funds: How Grants Flow During Recessions. Nonprofit and Voluntary Sector Quarterly, 48(5), 1066-1093.

Herzog, P. S., \& Yang, S. (2018). Social Networks and Charitable Giving: Trusting, Doing, Asking, and Alter Primacy. Nonprofit and Voluntary Sector Quarterly, 47(2), 376-394.

Hungerman, D. M. (2008). Race and Charitable Church Activity. Economic Inquiry, 46(3), 380400.

Longhofer, W., Negro, G., \& Roberts, P. W. (2019). The Changing Effectiveness of Local Civic Action: The Critical Nexus of Community and Organization. Administrative Science Quarterly, 64(1), 203-229.

Madoff, R. D. (2016, November). Charities and Taxpayers Deserve More From Donor-Advised Funds. Chronicle of Philanthropy, 53.

Miguel, E., \& Gugerty, M. K. (2005). Ethnic diversity, social sanctions, and public goods in Kenya. Journal of Public Economics, 89(11-12), 2325-2368. 
Montalvo, J. G., \& Reynal-Querol, M. (2002). Why ethnic fractionalization? Polarization, ethnic conflict and growth. In Economics Working Papers (No. 660; Economics Working Papers). Department of Economics and Business, Universitat Pompeu Fabra. https://ideas.repec.org/p/upf/upfgen/660.html

National Philanthropic Trust (NPT) (2019). The 2019 DAF Report. https://www.nptrust.org/reports/daf-report/

Okten, C., \& Osili, U. O. (2004). Contributions in Heterogeneous Communities: Evidence from Indonesia. Journal of Population Economics, 17(4), 603-626.

Okten, C., \& Weisbrod, B. A. (2000). Determinants of donations in private nonprofit markets. Journal of Public Economics, 75(2), 255-272.

Ostrander, S. A. (2007). The Growth of Donor Control: Revisiting the Social Relations of Philanthropy. Nonprofit and Voluntary Sector Quarterly, 36(2), 356-372.

Paarlberg, L. E., Johnson, J. M., \& Hannibal, B. (2019). Race and the public foundation grants marketplace: The differential effect of network status in communities of colour. Public Management Review, $0(0), 1-21$.

Paarlberg, L. E., \& Zuhlke, S. (2019). Revisiting the Theory of Government Failure in the Face of Heterogeneous Demands. Perspectives on Public Management and Governance, 2(2), 103-124.

Perry, D. C., \& Mazany, T. (2014). Community Foundatins as Foundations of Community. In Here for Good: Community Foundations and the Challenges of the 21st Century (pp. 225). ME Sharpe. 
Philipp, A., \& Mazany, T. (2015). The Special Standing of Community Foundations as Sponsors of Donor-Advised Funds. Forum on Philanthropy and the Public Good. https://lawdigitalcommons.bc.edu/philanthropy-forum/donoradvised2015/papers/12 Phillips, S. D., \& Jung, T. (2016). Concluding Thoughts: The 'Ubers' of Philanthropy and Future Disruptions. 24.

Poteete, A. R., \& Ostrom, E. (2004). Heterogeneity, Group Size and Collective Action: The Role of Institutions in Forest Management. Development and Change, 35(3), 435-461.

Poterba, J. M. (1997). Demographic structure and the political economy of public education. Journal of Policy Analysis and Management, 16(1), 48-66.

Putnam, R. D. (2000). Bowling Alone: The Collapse and Revival of American Community. Simon and Schuster.

Putnam, R. D. (2007). E Pluribus Unum: Diversity and Community in the Twenty-first Century The 2006 Johan Skytte Prize Lecture. Scandinavian Political Studies, 30(2), 137-174.

Reich, R. (2018). Just Giving: Why Philanthropy Is Failing Democracy and How It Can Do Better. Princeton University Press.

Reich, R., Bernholz, L., \& Cordelli, C. (2016). Philanthropy in Democratic Societies: History, Institutions, Values. University of Chicago Press.

Rotolo, T., \& Wilson, J. (2012). State-Level Differences in Volunteerism in the United States: Research Based on Demographic, Institutional, and Cultural Macrolevel Theories. Nonprofit and Voluntary Sector Quarterly, 41(3), 452-473.

Rupasingha, A., Goetz, S. J., \& Freshwater, D. (2006). The production of social capital in US counties. The Journal of Socio-Economics, 35(1), 83-101. 
Sampson, R. J., \& Graif, C. (2009). Neighborhood Social Capital as Differential Social Organization: Resident and Leadership Dimensions. American Behavioral Scientist, 52(11), 1579-1605.

Schneider, J. C. (1996). Philanthropic Styles in the United States: Toward a Theory of Regional Differences. Nonprofit and Voluntary Sector Quarterly, 25(2), 190-210.

Semuels, A. (2018, May 14). The "Black Hole" That Sucks Up Silicon Valley's Money. The Atlantic. https://www.theatlantic.com/technology/archive/2018/05/silicon-valleycommunity-foundation-philanthropy/560216/

Stichnoth, H., \& Van der Straeten, K. (2013). Ethnic diversity, public spending, and individual support for the welfare state: A review of the empirical literature. Journal of Economic Surveys, 27(2), 364-389.

Tajfel, H., Billig, M., Bundy, R., \& Flament, C. (1971). Social categorization and intergroup behavior. European Journal of Social Psychology, 1, 149-178.

Tinkelman. (1999). Factors affecting the relation between donations to not-for-profit organizations and an efficiency ratio. Government and Nonprofit Accounting, 10(1), 135161.

Tinkelman, D., \& Mankaney, K. (2007). When is Administrative Efficiency Associated With Charitable Donations? Nonprofit and Voluntary Sector Quarterly, 36(1), 41-64.

Trounstine, J. (2016). Segregation and Inequality in Public Goods. American Journal of Political Science, 60(3), 709-725.

Vigdor, J. L. (2004). Community composition and collective action: Analyzing initial mail response to the 2000 census. Review of Economics and Statistics, 86(1), 303-312. 
Weisbrod, B. A., \& Dominguez, N. D. (1986). Demand for collective goods in private nonprofit markets: Can fundraising expenditures help overcome free-rider behavior? Journal of Public Economics, 30(1), 83-96. 
Table 1 Descriptive Statistics

\begin{tabular}{|l|c|c|c|c|c|}
\hline & \multicolumn{2}{|c|}{ DAF sponsors } & Non-DAF sponsors & \\
\hline Variable & Mean & SD & Mean & SD & $\begin{array}{c}\text { t-test p- } \\
\text { value }\end{array}$ \\
\hline Contributions to DAFs (\$) & $8.68 \mathrm{M}$ & $83.70 \mathrm{M}$ & 0 & 0 & - \\
\hline Contributions to DAFs (log) & 13.08 & 2.55 & 0 & 0 & - \\
\hline Non-DAF contributions (\$) & $4.03 \mathrm{M}$ & $11.30 \mathrm{M}$ & 426,253 & $1.71 \mathrm{M}$ & $* * * *$ \\
\hline Non-DAF contributions (log) & 13.97 & 2.00 & 10.85 & 3.23 & $* * * *$ \\
\hline Total contributions (\$) & $12.70 \mathrm{M}$ & $85.50 \mathrm{M}$ & 426,253 & $1.71 \mathrm{M}$ & $* * * *$ \\
\hline Total contributions (log) & 14.64 & 1.72 & 10.85 & 3.23 & $* *$ \\
\hline Ethnic-racial diversity (FI) & 0.34 & 0.18 & 0.32 & 0.21 & \\
\hline Ethnic-racial polarization (QR) & 0.52 & 0.24 & 0.50 & 0.27 & \\
\hline Social capital index (standardized) & -0.13 & 0.89 & 0.01 & 1.26 & $*$ \\
\hline Median household income (\$) & 51,294 & 11,576 & 52,519 & 14,559 & \\
\hline Median household income (log) & 10.82 & 0.22 & 10.83 & 0.26 & \\
\hline Income inequality & 1.30 & 0.08 & 1.31 & 0.09 & \\
\hline College education or higher (\%) & 24.81 & 9.81 & 25.22 & 10.83 & \\
\hline Median age & 39.55 & 4.18 & 40.09 & 4.68 & \\
\hline Population served (log) & 12.25 & 1.47 & 11.53 & 1.86 & $* * * *$ \\
\hline Number of service areas & 3.65 & 7.45 & 1.20 & 0.88 & $* * * *$ \\
\hline Fundraising expenses (log) & 3.60 & 4.98 & 2.37 & 4.27 & $* * *$ \\
\hline Program expense ratio & 0.66 & 0.19 & 0.58 & 0.34 & $* * * *$ \\
\hline Organizational age in 2016 & 28.10 & 16.21 & 23.67 & 13.07 & $* * * *$ \\
\hline Total assets (log) & 16.94 & 1.67 & 14.20 & 1.44 & $* * * *$ \\
\hline
\end{tabular}

\begin{tabular}{|l|l|l|l|l|l|}
\hline Sponsor DAFs & Northeast & Midwest & South & West & $\begin{array}{l}\chi^{2} \text { test } \\
\text { p-value }\end{array}$ \\
\hline No & $21(23.6 \%)$ & $86(25.1 \%)$ & $31(19.5 \%)$ & $51(34.5 \%)$ & \\
\hline Yes & $68(76.4 \%)$ & $256(74.8 \%)$ & $128(80.5 \%)$ & $97(65.5 \%)$ & \\
\hline Total & $89(100 \%)$ & $342(100 \%)$ & $159(100 \%)$ & $148(100 \%)$ & $* *$ \\
\hline
\end{tabular}

$\mathrm{N}=738,549$ DAF sponsors and 189 non-DAF sponsors. All dollar amounts are inflation adjusted to 2017 dollars. ${ }^{*} p$ $<0.10,{ }^{* *} p<0.05,{ }^{* * *} p<0.01,{ }^{* * * *} p<0.001$. 
Table 2 Logistic regressions on the probability of sponsoring DAFs

\begin{tabular}{|c|c|c|}
\hline & Coef & Average marginal effects \\
\hline Ethnic-racial diversity (FI) & $\begin{array}{c}0.742 \\
(1.349)\end{array}$ & $\begin{array}{l}0.0740 \\
(0.134)\end{array}$ \\
\hline Social capital index & $\begin{array}{l}0.0429 \\
(0.164)\end{array}$ & $\begin{array}{l}0.00428 \\
(0.0163)\end{array}$ \\
\hline Income inequality & $\begin{array}{l}-2.519 \\
(2.005)\end{array}$ & $\begin{array}{l}-0.251 \\
(0.200)\end{array}$ \\
\hline Median household income & $\begin{array}{l}-0.530 \\
(0.925)\end{array}$ & $\begin{array}{c}-0.0528 \\
(0.0928)\end{array}$ \\
\hline College education or more & $\begin{array}{l}-0.00179 \\
(0.0237)\end{array}$ & $\begin{array}{c}-0.000179 \\
(0.00236)\end{array}$ \\
\hline Median county age & $\begin{array}{l}-0.187 \\
(0.272)\end{array}$ & $\begin{array}{l}0.000734 \\
(0.00334)\end{array}$ \\
\hline Median county age squared & $\begin{array}{c}0.00242 \\
(0.00327)\end{array}$ & \\
\hline Service areas & $\begin{array}{l}0.739^{* *} \\
(0.303)\end{array}$ & $\begin{array}{l}0.0737^{* *} \\
(0.0296)\end{array}$ \\
\hline Population & $\begin{array}{l}0.0956 \\
(0.151)\end{array}$ & $\begin{array}{l}0.00953 \\
(0.0150)\end{array}$ \\
\hline Fundraising expenses & $\begin{array}{c}0.0867^{* * *} \\
(0.0300)\end{array}$ & $\begin{array}{l}0.00864^{* * *} \\
(0.00289)\end{array}$ \\
\hline Program expense ratio & $\begin{array}{l}0.0597 \\
(0.524)\end{array}$ & $\begin{array}{l}0.00596 \\
(0.0522)\end{array}$ \\
\hline Organizational age & $\begin{array}{c}-0.1000^{* * *} \\
(0.0363)\end{array}$ & $\begin{array}{c}-0.00490^{* * * * *} \\
(0.00146)\end{array}$ \\
\hline Organizational age squared & $\begin{array}{c}0.00105^{* *} \\
(0.000460)\end{array}$ & \\
\hline Total assets & $\begin{array}{c}1.200^{* * * *} \\
(0.118)\end{array}$ & $\begin{array}{l}0.120^{* * * *} \\
(0.00534)\end{array}$ \\
\hline Constant & $\begin{array}{l}-5.696 \\
(11.64) \\
\end{array}$ & \\
\hline pseudo $R^{2}$ & .440 & \\
\hline
\end{tabular}

$\mathrm{N}=738$. Total number of service areas is transformed using its square root. Region is included. All dollar amounts are inflation adjusted to 2017 dollars. Robust standard errors in parentheses. ${ }^{*} p<0.10,{ }^{* *} p<0.05,{ }^{* * *} p<0.01,{ }^{* * * *} p<0.001$. 
Table 3 Tobit regressions on non-DAF contributions

\begin{tabular}{|c|c|c|}
\hline & DAF Sponsors & Non-DAF Sponsors \\
\hline Ethnic-racial diversity (FI) & $\begin{array}{c}0.664 \\
(0.658)\end{array}$ & $\begin{array}{c}-2.664 \\
(1.940)\end{array}$ \\
\hline Social capital index & $\begin{array}{l}0.0584 \\
(0.100)\end{array}$ & $\begin{array}{c}0.107 \\
(0.271)\end{array}$ \\
\hline Income inequality & $\begin{array}{c}-0.645 \\
(1.796)\end{array}$ & $\begin{array}{c}3.657 \\
(2.854)\end{array}$ \\
\hline Median household income & $\begin{array}{c}0.234 \\
(0.523)\end{array}$ & $\begin{array}{l}-1.479 \\
(1.428)\end{array}$ \\
\hline College education or more & $\begin{array}{l}0.00605 \\
(0.0143)\end{array}$ & $\begin{array}{c}0.0240 \\
(0.0391)\end{array}$ \\
\hline Median county age & $\begin{array}{l}-0.178 \\
(0.141)\end{array}$ & $\begin{array}{c}0.832 \\
(0.624)\end{array}$ \\
\hline Median county age squared & $\begin{array}{c}0.00215 \\
(0.00177)\end{array}$ & $\begin{array}{c}-0.0101 \\
(0.00727)\end{array}$ \\
\hline Service areas & $\begin{array}{l}0.214^{* * *} \\
(0.0713)\end{array}$ & $\begin{array}{c}2.035^{* * *} \\
(0.722)\end{array}$ \\
\hline Population & $\begin{array}{l}-0.0361 \\
(0.0959)\end{array}$ & $\begin{array}{l}0.0264 \\
(0.241)\end{array}$ \\
\hline Fundraising expenses & $\begin{array}{c}0.0381^{* * *} \\
(0.0118)\end{array}$ & $\begin{array}{c}0.0513 \\
(0.0627)\end{array}$ \\
\hline Program expense ratio & $\begin{array}{l}-0.419 \\
(0.627)\end{array}$ & $\begin{array}{c}-0.0124 \\
(0.721)\end{array}$ \\
\hline Organizational age & $\begin{array}{c}0.00931 \\
(0.0142)\end{array}$ & $\begin{array}{l}-0.0621 \\
(0.0629)\end{array}$ \\
\hline Organizational age squared & $\begin{array}{c}-0.0000685 \\
(0.000153)\end{array}$ & $\begin{array}{c}0.000928 \\
(0.000815)\end{array}$ \\
\hline Total assets & $\begin{array}{l}0.805^{* * * *} \\
(0.0510)\end{array}$ & $\begin{array}{l}0.0274 \\
(0.221)\end{array}$ \\
\hline Constant & $\begin{array}{c}1.914 \\
(8.266) \\
\end{array}$ & $\begin{array}{c}3.427 \\
(19.24)\end{array}$ \\
\hline $\begin{array}{l}N \\
\text { pseudo } R^{2}\end{array}$ & $\begin{array}{c}521 \\
0.171\end{array}$ & $\begin{array}{c}189 \\
0.025\end{array}$ \\
\hline
\end{tabular}


Table 4 OLS regressions on contributions to DAFs and ethnic-racial diversity

\begin{tabular}{|c|c|c|c|}
\hline & All DAF Sponsors & Service area $=1$ & Service area $>1$ \\
\hline Ethnic-racial diversity (FI) & $\begin{array}{l}1.864^{* *} \\
(0.781)\end{array}$ & $\begin{array}{c}2.946^{* * *} \\
(1.045)\end{array}$ & $\begin{array}{l}-0.0972 \\
(1.284)\end{array}$ \\
\hline Social capital index & $\begin{array}{c}0.204^{*} \\
(0.118)\end{array}$ & $\begin{array}{c}0.323^{*} \\
(0.194)\end{array}$ & $\begin{array}{c}0.140 \\
(0.153)\end{array}$ \\
\hline Income inequality & $\begin{array}{c}1.303 \\
(1.242)\end{array}$ & $\begin{array}{c}2.474 \\
(1.677)\end{array}$ & $\begin{array}{l}-1.674 \\
(2.075)\end{array}$ \\
\hline Median household income & $\begin{array}{c}0.369 \\
(0.542)\end{array}$ & $\begin{array}{c}0.992 \\
(0.905)\end{array}$ & $\begin{array}{l}-0.127 \\
(0.703)\end{array}$ \\
\hline College education or more & $\begin{array}{c}0.0257^{*} \\
(0.0139)\end{array}$ & $\begin{array}{l}0.00743 \\
(0.0207)\end{array}$ & $\begin{array}{l}0.0474^{* *} \\
(0.0199)\end{array}$ \\
\hline Median county age & $\begin{array}{c}-0.182 \\
(0.197)\end{array}$ & $\begin{array}{l}-0.322 \\
(0.237)\end{array}$ & $\begin{array}{c}0.224 \\
(0.566)\end{array}$ \\
\hline Median county age squared & $\begin{array}{c}0.00183 \\
(0.00244)\end{array}$ & $\begin{array}{c}0.00365 \\
(0.00287)\end{array}$ & $\begin{array}{c}-0.00397 \\
(0.00729)\end{array}$ \\
\hline Service areas & $\begin{array}{c}0.205^{* * *} \\
(0.0723)\end{array}$ & & $\begin{array}{l}0.204^{* *} \\
(0.102)\end{array}$ \\
\hline Population & $\begin{array}{c}0.0248 \\
(0.0943)\end{array}$ & $\begin{array}{c}-0.0188 \\
(0.122)\end{array}$ & $\begin{array}{c}0.164 \\
(0.161)\end{array}$ \\
\hline Fundraising expenses & $\begin{array}{l}0.0397^{* * *} \\
(0.0129)\end{array}$ & $\begin{array}{c}0.0640^{* * * *} \\
(0.0167)\end{array}$ & $\begin{array}{r}-0.00420 \\
(0.0214)\end{array}$ \\
\hline Program expense ratio & $\begin{array}{c}1.883^{* * * *} \\
(0.432)\end{array}$ & $\begin{array}{c}2.062^{* * * *} \\
(0.554)\end{array}$ & $\begin{array}{c}1.276^{*} \\
(0.698)\end{array}$ \\
\hline Organizational age & $\begin{array}{c}-0.0358^{* *} \\
(0.0167)\end{array}$ & $\begin{array}{l}-0.0225 \\
(0.0195)\end{array}$ & $\begin{array}{l}-0.0606^{*} \\
(0.0325)\end{array}$ \\
\hline Organizational age squared & $\begin{array}{c}0.000336^{*} \\
(0.000191)\end{array}$ & $\begin{array}{c}0.000183 \\
(0.000222)\end{array}$ & $\begin{array}{c}0.000584 \\
(0.000385)\end{array}$ \\
\hline Total assets & $\begin{array}{l}0.873^{* * * *} \\
(0.0548)\end{array}$ & $\begin{array}{l}0.866^{* * * *} \\
(0.0703)\end{array}$ & $\begin{array}{l}0.925^{* * * *} \\
(0.0945)\end{array}$ \\
\hline Constant & $\begin{array}{r}-5.954 \\
(6.667) \\
\end{array}$ & $\begin{array}{l}-10.93 \\
(9.509) \\
\end{array}$ & $\begin{array}{l}-5.465 \\
(13.32)\end{array}$ \\
\hline $\begin{array}{l}N \\
R^{2} \\
\end{array}$ & $\begin{array}{c}549 \\
0.614 \\
\end{array}$ & $\begin{array}{c}357 \\
0.595\end{array}$ & $\begin{array}{c}192 \\
0.627 \\
\end{array}$ \\
\hline
\end{tabular}

Total number of service areas is transformed using its square root. Region is included. All dollar amounts are inflation adjusted to 2017 dollars. Robust standard errors in parentheses. ${ }^{*} p<0.10,{ }^{* *} p<0.05,{ }^{* * *} p<0.01,{ }^{* * * *} p<0.001$. 